\section{Prevalence of diabetic eye disease in an inner city population: the Liverpool Diabetic Eye Study}

Laser photocoagulation, given early in the course of the disease, is highly effective at preventing visual deterioration. ${ }^{2-6}$ Screening has been shown to be effective $e^{7-9}$ in detecting sight-threatening diabetic eye disease (STED) at justifiable costs. ${ }^{10-13}$ Computerised general practice and district diabetes registers are being developed for easier identification of target populations, ${ }^{14}$ and screening programmes have now been instituted in a number of locations in the UK. ${ }^{9,15}$

The St Vincent Declaration in 1990 set targets for diabetes care including the reduction of blindness by one-third. ${ }^{16}$ To demonstrate that such a target has been met in the future a measure of current baseline prevalence is required. Population-based data from the UK are restricted to a single study in an English town in $1988,{ }^{17,18}$ with data from other settings and other countries also available. ${ }^{19-28}$

The Liverpool Diabetic Eye Study (LDES) was established in 1991 to investigate screening for STED. In this report we present the profile of diabetes-related eye disease in a cohort of diabetic patients in inner city Liverpool to provide a baseline estimate of prevalence prior to the introduction of systematic screening.

\title{
Methods
}

As part of a systematic community-based screening programme all adult diabetic patients attending four inner city general practices, including those under the care of the hospital eye service, were identified from computerised practice registers. Underprivileged area scores (Jarman scores) based on the 1991 census, averaged for the electoral wards serving each practice, were used as an index of the potential workload or pressure on the services of the general practitioners in the study. ${ }^{29}$ Ethnic mix by electoral ward was recorded.

Patients were invited to attend for slit-lamp biomicroscopy and colour fundus photography. Slit-lamp biomicroscopy with 90 and 60 dioptre indirect lenses was performed in a hospitalbased clinic by a single consultant specialist in 
Table 1. Levels of retinopathy in the Liverpool Diabetic Eye Study

\section{Level Definition}

$10 \quad$ No retinopathy

20 Haemorrhages/microaneurysms only < ETDRS STD 2A

30 Haemorrhages/microaneurysms $\geqslant$ ETDRS STD 2A, \pm $<6$ CWS

$40 \geqslant 6$ CWS, \pm 1 quadrant venous changes, \pm IRMA $<$ ETDRS STD 8A

50 IRMA $\geqslant$ ETDRS STD $8 \mathrm{~A}, \pm 2$ or more quadrants venous changes \pm preretinal haemorrhage in the absence of proliferation

60 Fibrovascular proliferation, panretinal

photocoagulation, proliferative retinopathy

DRS high-risk characteristics ${ }^{38}$

71+ Vitreous haemorrhage, traction retinal detachment

$90 \quad$ Ungradable for any reason, e.g. media opacity

99 Unobtainable for any reason, e.g. wheelchair-bound

ETDRS STD, Early Treatment Diabetic Retinopathy Study standard photograph; ${ }^{30}$ IRMA, intraretinal microvascular anomaly; CWS, cotton wool spot; DRS, Diabetic Retinopathy Study.

medical retinal disease (S.P.H.). Photography was performed in the general practice centre using a Canon CR4-45NM camera, tropicamide 1\%, three overlapping non-stereoscopic $45^{\circ}$ fields and $35 \mathrm{~mm}$ transparencies as previously reported. ${ }^{9}$ Data on demography and management of diabetes were obtained by questionnaire. Type I insulin-dependent diabetes was defined as age at onset $<30$ years and/or definite insulin dependence (for example a single episode of ketoacidosis). Type II noninsulin-dependent diabetes was defined as age at diagnosis $\geqslant 30$ years in the absence of insulin dependence. Type II patients who required insulin subsequent to diagnosis were termed insulin-requiring (IR) and those who did not were termed non-insulinrequiring (NIR).

Visual acuity was measured using a Snellen chart at $6 \mathrm{~m}$ with each eye separately, unaided, with distance spectacles and with pinhole, and best acuity was recorded for each eye. An acuity of $\leqslant 6 / 24$ in the better eye was taken as an indicator of significant visual disability, as utilised by others. ${ }^{18}$

Modified Wisconsin grading in the LDES for retinopathy, macular exudates and macular oedema has been described previously ${ }^{9}$ and is presented here in summary in Tables 1-3. Levels of disease for each patient are given according to the worse eye. STED requiring referral to an ophthalmologist was defined as any of the

Table 2. Levels of maculopathy classified by exudate in the Liverpool Diabetic Eye Study

\begin{tabular}{ll}
\hline Level & Definition \\
\hline 0 & No maculopathy \\
1 & Questionable: $<50 \%$ certainty of the presence of exudate \\
2 & Exudate $>1$ disc diameter from fixation \\
3 & $\begin{array}{c}\text { Circinate ring of exudate within the macula }>1 \text { disc area } \\
\text { in size but not within } 1 \text { disc diameter of fixation }\end{array}$ \\
4 & $\begin{array}{l}\text { Exudates within } 1 \text { disc diameter of fixation } \pm \text { presence } \\
\text { of focal or grid photocoagulation scars }\end{array}$ \\
8 & $\begin{array}{l}\text { Non-diabetic macular exudate } \\
90\end{array}$ \\
\hline
\end{tabular}

Table 3. Levels of macular oedema in the Liverpool Diabetic Eye Study

\begin{tabular}{cl}
\hline Level & Definition \\
\hline 0 & No macular oedema \\
1 & Questionable: $<50 \%$ certainty of the presence of oedema \\
2 & $\begin{array}{l}\text { Macular oedema, but not clinically significant macular } \\
\text { oedema }\end{array}$ \\
3 & $\begin{array}{l}\text { Circinate ring but not clinically significant macular } \\
\text { oedema }\end{array}$ \\
4 & $\begin{array}{l}\text { Clinically significant macular oedema } \\
8\end{array}$ \\
Non-diabetic macular oedema \\
90 & Ungradable \\
\hline
\end{tabular}

${ }^{a}$ Early Treatment Diabetic Retinopathy Study definition of clinically significant macular oedema. ${ }^{30}$

following: moderate preproliferative retinopathy (level 40 ) or worse; circinate maculopathy (level 3), exudates within 1 disc diameter of fixation or clinically significant macular oedema ${ }^{30}$ (level 4); significant diabetes related other eye disease, e.g. retinal vascular occlusion.

\section{Results}

Between 1992 and 1994, 395 patients were identified and invited to take part in the study. Three hundred and twenty-six $(83 \%)$ attended for biomicroscopy. The sample size was increased to $357(90 \%)$ by including data from 31 patients who attended for photography but did not attend for biomicroscopy.

The total population of the four practices was 31856 , giving a point prevalence of $12.4 / 1000$. Underprivileged area (UPA) scores for the four practices were -17.07 , $1.22,31.95$ and 35.29 (overall range in Liverpool -30.35 to 56.67) and the percentages of all Asian persons were $0.47 \%, 1.38 \%, 0.35 \%$ and $0.77 \%$ respectively. The mean age of the study population was $60.3( \pm 16)$ years (range 13-92 years) with 188 males and 169 females. Forty-nine patients were type I, 40 type II IR and 268 type II NIR. Duration of diabetes after diagnosis was greater than 15 years in $40.9 \%$ of type I, $9.0 \%$ of type II and $13.4 \%$ overall. There was no significant difference between the demography of the main group and the 31 who had photography alone (mean age 60.9 years, range 27-92 years; M 15, F 16; type I 5, IR type II 3, NIR type II 23).

In the photography group, 9 of 31 patients were ungradable for retinopathy and maculopathy due to media opacity. Two patients who were ungradable for retinopathy were gradable for maculopathy. A further 2 patients in the biomicroscopy group were ungradable for maculopathy but gradable for retinopathy.

The prevalence of retinopathy categorised by type of diabetes management is presented in Table 4. Data for maculopathy are separated into gradings by macular exudate (Table 5) and macular oedema (Table 6, grading of biomicroscopy group only). Cumulative data are summarised in Table 7.

Data on visual function existed in 358 patients, including a known patient registered blind due to myopic degeneration who refused further examination. In the remaining 357 patients visual acuity (VA) in both eyes was $6 / 9$ or better in $72 \%$ and $6 / 24$ or better in $92 \%$. 
Table 4. Prevalence of levels of retinopathy in the worse eye by disease category

\begin{tabular}{|c|c|c|c|c|c|c|c|c|}
\hline \multirow[b]{3}{*}{ Level } & \multicolumn{8}{|c|}{ Type of diabetes control } \\
\hline & \multicolumn{2}{|c|}{ ID } & \multicolumn{2}{|c|}{ IR } & \multicolumn{2}{|c|}{ NIR } & \multicolumn{2}{|c|}{ All } \\
\hline & $n$ & $\%$ & $n$ & $\%$ & $n$ & $\%$ & $n$ & $\%$ \\
\hline 10 & 31 & 63.3 & 22 & 55.0 & 171 & 63.8 & 224 & 62.7 \\
\hline 20 & 11 & 22.4 & 12 & 30.0 & 52 & 19.4 & 75 & 21.0 \\
\hline 30 & 3 & 6.1 & 2 & 5.0 & 24 & 9.0 & 29 & 8.1 \\
\hline 40 & 3 & 6.1 & 4 & 10.0 & 3 & 1.1 & 10 & 2.8 \\
\hline 50 & 0 & & 0 & & 2 & 0.7 & 2 & 0.6 \\
\hline 60 & 0 & & 0 & & 0 & & 0 & \\
\hline 70 & 1 & 2.0 & 0 & & 2 & 0.7 & 3 & 0.8 \\
\hline 71 & 0 & & 0 & & 1 & 0.4 & 1 & 0.3 \\
\hline 90 & 0 & & 0 & & 11 & 4.1 & 11 & 3.1 \\
\hline 99 & 0 & & 0 & & 2 & 0.7 & 2 & 0.6 \\
\hline Total & 49 & 100 & 40 & 100 & 268 & 100 & 357 & 100 \\
\hline
\end{tabular}

ID, insulin-dependent; IR, insulin-requiring; NIR, non-insulin-requiring.

A VA of $\leqslant 6 / 24$ in both eyes occurred in $3.1 \%$ of patients (type I: 1, type II IR: 3, type II NIR: 7). In 2 (0.6\%), both type II NIR patients, VA was $\leqslant 6 / 60$ in both eyes due to age-related macular degeneration and posterior capsular thickening respectively. In the remaining 9 patients reduced VA between $6 / 24$ and $6 / 60$ was attributable to diabetic eye disease in $3(0.8 \%)$, of whom 2 were type II IR. In one further type II NIR patient VA was below 2/60 in one eye due to diabetic eye disease, and in 2 patients VA was $\leqslant 6 / 60$ in one eye due to retinal vascular occlusion. No patient had a VA at or below the standard for legal blindness $(2 / 60$ or worse) or the standard for partially sighted registration $(6 / 60$ or worse) due to diabetic eye disease.

One hundred and nine (33\%) patients were found to have cataract, of whom $42(13 \%)$ required cataract extraction. Thirty $(9.2 \%)$ patients had a cup/disc ratio $\geqslant 0.6$ or raised intraocular pressure requiring further investigation. Follow-up revealed primary open angle glaucoma in 7 patients (5 previously undiagnosed), normal tension glaucoma in 1 and ocular hypertension in 3. Nineteen patients had normal fields and intraocular pressure but cupped discs. Significant age-related macular degeneration (changes of age-related maculopathy with VA $<6 / 9$ in the absence of another cause of reduced vision) was found in 78 patients and retinal vascular occlusion in 5 . There were 3 cases of choroidal neovascularisation and 1 malignant melanoma.

\section{Discussion}

This study provides essential data on the baseline prevalence of diabetic eye disease in a defined population in an inner city setting. In terms of UPA scores the four practices were felt to be representative of Liverpool as a whole. The prevalence of any retinopathy was $33.6 \%$, of proliferative retinopathy $1.1 \%$ and of clinically significant macular oedema (CSMO) $6.4 \%$.

Moderate preproliferative retinopathy or worse was present in $4.5 \%$ of patients, and $9.2 \%$ had macular exudates within 1 disc diameter of fixation or significant circinate maculopathy. These are patients who require referral and follow-up by an ophthalmologist according to our criteria and in line with those of the European Retinopathy Working Party. ${ }^{31}$ The prevalence of STED in our population was high at $13.4 \%$, indicating a considerable morbidity and justifying expenditure on detection and treatment.

Screening for diabetic eye disease in Liverpool prior to this study comprised opportunistic direct ophthalmoscopy by general practitioners, diabetologists and optometrists without central co-ordination, training or audit. The impact of such screening is difficult to measure accurately. However, our findings are likely to be typical of the majority of locations in the UK where systematic screening is yet to be widely implemented.

Table 5. Prevalence of levels of maculopathy as classified by macular exudates in the worse eye by disease category

\begin{tabular}{|c|c|c|c|c|c|c|c|c|}
\hline \multirow[b]{3}{*}{ Level } & \multicolumn{8}{|c|}{ Type of diabetes control } \\
\hline & \multicolumn{2}{|c|}{ ID } & \multicolumn{2}{|c|}{ IR } & \multicolumn{2}{|c|}{ NIR } & \multicolumn{2}{|c|}{ All } \\
\hline & $n$ & $\%$ & $n$ & $\%$ & $n$ & $\%$ & $n$ & $\%$ \\
\hline 0 & 44 & 89.8 & 31 & 77.5 & 226 & 84.3 & 301 & 84.3 \\
\hline 1 & 0 & & 1 & 2.5 & 1 & 0.4 & 2 & 0.6 \\
\hline 2 & 2 & 4.1 & 0 & & 5 & 1.9 & 7 & 2.0 \\
\hline 3 & 0 & & 0 & & 2 & 0.7 & 2 & 0.6 \\
\hline 4 & 2 & 4.1 & 7 & 17.5 & 22 & 8.2 & 31 & 8.7 \\
\hline 8 & 0 & & 0 & & 1 & 0.4 & 1 & 0.3 \\
\hline 90 & 1 & 2.0 & 1 & 2.5 & 9 & 3.4 & 11 & 3.1 \\
\hline 99 & 0 & & 0 & & 2 & 0.7 & 2 & 0.6 \\
\hline Total & 49 & 100 & 40 & 100 & 268 & 100 & 357 & 100 \\
\hline
\end{tabular}

ID, insulin-dependent; IR, insulin-requiring; NIR, non-insulin-requiring. 


\begin{tabular}{|c|c|c|c|c|c|c|c|c|}
\hline \multirow[b]{3}{*}{ Level } & \multicolumn{8}{|c|}{ Type of diabetes control } \\
\hline & \multicolumn{2}{|c|}{ ID } & \multicolumn{2}{|c|}{ IR } & \multicolumn{2}{|c|}{ NIR } & \multicolumn{2}{|c|}{ All } \\
\hline & $n$ & $\%$ & $n$ & $\%$ & $n$ & $\%$ & $n$ & $\%$ \\
\hline 0 & 40 & 91.0 & 27 & 73.0 & 217 & 87.9 & 284 & 86.6 \\
\hline 1 & 0 & & 1 & 2.7 & 4 & 1.6 & 5 & 1.5 \\
\hline 2 & 2 & 4.5 & 1 & 2.7 & 2 & 0.8 & 5 & 1.5 \\
\hline 3 & 0 & & 0 & & 3 & 1.2 & 3 & 0.9 \\
\hline 4 & 1 & 2.3 & 6 & 16.2 & 14 & 5.7 & 21 & 6.4 \\
\hline 8 & 0 & & 1 & 2.7 & 1 & 0.4 & 2 & 0.6 \\
\hline 90 & 1 & 2.3 & 1 & 2.7 & 4 & 1.6 & 6 & 1.8 \\
\hline 99 & 0 & & 0 & & 2 & 0.8 & 2 & 0.6 \\
\hline Total & 44 & 100 & 37 & 100 & 247 & 100 & 328 & 100 \\
\hline
\end{tabular}

ID, insulin-dependent; IR, insulin-requiring; NIR, non-insulin-requiring.

Patients in each category who did not undergo biomicroscopy (i.e. photographs only): ID, 5; IR, 3; NID, 21.

Our estimate of baseline prevalence may be an underestimate. The attendance rate at the hospital clinic for biomicroscopy was over $80 \%$, but in order to increase the sample size we added a group of patients who were not prepared to attend hospital and who only had photography. Obviously no measure for CSMO is possible in the photography-only group. The sensitivity of the photographic protocol used in this study has been previously reported by us as $89 \%{ }^{9}$ and by others as $81 \%,{ }^{8}$ and so a small number of cases may have been missed. In addition, 11 patients in the photography group were ungradable, increasing the possibility of underestimation.

Our point prevalence of $12.4 / 1000$ is similar to previous studies: Reenders et al. 14.5/1000, ${ }^{28}$ Melton Mowbray $10.9 / 1000,{ }^{17,18}$ WESDR 9.7/1000. ${ }^{32}$ Our study used a similar case acquisition to previous studies, but may have been incomplete as evidenced by a recently developed diabetes register in Scotland which has reported a prevalence of diabetes of $19.4 / 1000 .^{33}$ General practice diabetes registers can also miss up to $18 \%$ of known diabetics. ${ }^{33}$ Liverpool has a low proportion of ethnic minority groups (overall $96.23 \%$ of the population are white), and in particular a low proportion of Asian persons, which may explain our lower prevalence of diabetes.

Other researchers have measured prevalence in selected groups. Reenders et al. ${ }^{28}$ reported a prevalence of any retinopathy of only $14 \%$ in a well-defined Dutch population. Their low estimate was probably due to poor sensitivity of direct ophthalmoscopy by general practitioners and a compliance rate of only $76 \%$. Other groups have found higher prevalences. Kristinsson et al. ${ }^{24}$ performed biomicroscopy on $90 \%$ of all type I diabetics in Iceland and found retinopathy in 52\% and proliferative retinopathy in $13 \%$. They also reported any retinopathy in $41 \%$, proliferative retinopathy in $7 \%$ and CSMO in $10 \%$ of 245 patients (one-fifth of the total population) of type II diabetics in Iceland. ${ }^{25}$ Agardh et al. ${ }^{26,27}$ reported retinopathy in $51.8 \%$ of diabetics attending a hospital service in Sweden, and Grey et al. ${ }^{22}$ found retinopathy in $43.4 \%$ of insulin-dependent and $20.1 \%$ of non-insulin-dependent diabetics attending a hospital diabetic clinic in Bristol in 1981. In a retrospective cross-sectional study of insulin-treated patients in Denmark, Sjølie ${ }^{23}$ reported an overall prevalence of any retinopathy of $41 \%$. However, data on up to one-third of patients were missing and examinations had been carried out over a 5-year period.

More direct comparison of the findings from our study is possible with two population studies: the Wisconsin Epidemiologic Study of Diabetic Retinopathy (WESDR) in the USA in 1980-2 $2^{19-22}$ and the Melton Mowbray (MM) study from the UK in $1987 .{ }^{17,18}$ In the WESDR a weighted stratification was used to select a sample of 1370 from 5431 diabetics identified from health records whose age at onset was over 30 years, while all younger-onset diabetics were included. The proportion

Table 7. Clinically relevant frequencies of retinopathy and maculopathy in the worse eye by disease category

\begin{tabular}{|c|c|c|c|c|c|}
\hline & & $\begin{array}{c}\text { All (\%) } \\
(n=357)\end{array}$ & $\begin{array}{c}\text { Type } 1(\%) \\
(n=49)\end{array}$ & $\begin{array}{c}\text { IR type II }(\%) \\
\quad(n=40)\end{array}$ & $\begin{array}{c}\text { NIR type II }(\%) \\
(n=268)\end{array}$ \\
\hline \multicolumn{6}{|l|}{ Retinopathy } \\
\hline Any retinopathy & $(20+)$ & 33.6 & 36.7 & 45.0 & 31.3 \\
\hline Referable retinopathy & $(40+)$ & 4.5 & 8.2 & 10.0 & 3.0 \\
\hline Requiring treatment & $(50+)$ & 1.4 & 2.0 & 0 & 1.9 \\
\hline Proliferative & $(60+)$ & 1.1 & 2.0 & 0 & 1.1 \\
\hline \multicolumn{6}{|l|}{ Maculopathy } \\
\hline \multicolumn{2}{|c|}{ Referable (exudate levels $3+4$ ) } & 9.2 & 4.1 & 17.5 & 9.0 \\
\hline $\mathrm{CSMO}$ & level 4) & 6.4 & 2.3 & 16.2 & 5.7 \\
\hline \multicolumn{2}{|l|}{ STED } & 13.4 & 10.2 & 25.0 & 12.3 \\
\hline
\end{tabular}

Figures shown are percentages of patients with both eyes gradable.

IR, insulin-requiring; NIR, non-insulin-requiring; CSMO, clinically significant macular oedema; ${ }^{30}$ STED, sight-threatening eye disease. 
of older-onset patients requiring insulin was high, at $49.2 \%$ (LDES $11.2 \%$ ). The MM study reported prevalence in a rural English town. However, patients on insulin were not divided into insulin-dependent and insulinrequiring groups. Compliance rates in our study at $89.9 \%$ were higher than in the other two: MM 75.4\%, WESDR $79.1 \%$.

In the LDES, the prevalences of retinopathy in type I diabetics were considerably lower than in the WESDR (any retinopathy: WESDR 70.4\%, LDES 36.7\%; proliferative/advanced retinopathy: WESDR $21.9 \%$, LDES $2.0 \%$; CSMO: WESDR $11.1 \%$, LDES 2.3\%).

Combining our data in the type I and insulin-requiring type II groups shows that there has been little change over the 6 years since the MM study in the rate of any retinopathy (MM 41\%, LDES 40.4\%) and of CSMO (MM $6.8 \%$, LDES $8.6 \%$ ), although a substantial fall in the prevalence of proliferative/advanced disease (MM 8\%, LDES $1.1 \%$ ). These reductions in disease may reflect baseline differences in clinical practice and glycaemic control and changes over the intervening 13 years between the first and the third study. Other factors might include the smaller proportion of ethnic minorities in Liverpool, although the racial mix in Wisconsin is not commented on in the WESDR reports.

Little impact has been made on the prevalences of all categories of retinopathy in the non-insulin-requiring type II group in all three centres. The presence of any retinopathy was recorded in $39.0 \%$ of older-onset patients in the WESDR, 52\% in the MM study and 31.3\% in the LDES, and of proliferative/advanced disease in $2.8 \%$ in the WESDR, $4 \%$ in the MM study and $1.1 \%$ in the LDES. Similarly, the prevalence of CSMO remains high at $3.7 \%$ in the WESDR and $5.7 \%$ in the LDES, with a surprisingly high estimate of $10 \%$ in the MM study. Undoubtedly this reflects the difficulties in identification of type II patients, up to $20 \%$ of whom already have retinopathy at the time of diagnosis. ${ }^{34}$ Little progress with this group seems likely without earlier diagnosis, which is probably dependent on better screening for diabetes. ${ }^{35}$

Our study confirms previous reports that the requirement for insulin in older-onset diabetics confers an especially high risk for the development of eye disease. Numbers in our study are small, but the highest prevalences of preproliferative disease $(15.0 \%)$ and CSMO (16.2\%) were found in this group. Similarly, the WESDR found the highest levels of preproliferative disease in their insulin-requiring older-onset group, although proliferative disease was higher in the youngeronset group. Of their older-onset insulin-requiring patients, $15.2 \%$ had macular oedema compared with only $3.7 \%$ in the non-insulin-requiring group. The higher levels of retinopathy in the insulin-requiring type II group are probably due to prolonged exposure to hyperglycaemia and possibly delay in the initiation of insulin treatment. Targeting such high-risk groups with increased health resources is essential.
Both the WESDR and the LDES found higher prevalences of CSMO in the insulin groups (combining type I and type II IR: WESDR $12.8 \%$, LDES $8.6 \%$ ) compared with the non-insulin-requiring type II group (WESDR 3.7\%, LDES 5.7\%), refuting the commonly held belief that maculopathy is commoner in type II diabetics and retinopathy commoner in type $\mathrm{I}^{36}$

In the MM study a VA of $6 / 60$ or less occurred in $4.0 \%$ overall $(1.5 \%$ of insulin-taking patients and $6.0 \%$ of type II diabetics), although in the latter group the cause for the poor VA is not stated. In type I patients the prevalence of VA in the better eye of $6 / 60$ or worse was $3.6 \%$ in the $\mathrm{WESDR}^{37}$ and $1.0 \%$ in Iceland, ${ }^{24}$ and in type II was $1.6 \%$ in the WESDR and $1.6 \%$ in Iceland. ${ }^{25}$ In our population only $3(0.8 \%)$ patients had a VA in the better eye of $6 / 60$ or worse, none due to diabetic eye disease. Significant visual morbidity due to diabetic eye disease was found in 7 eyes of 4 patients. Overall rates of blindness and partial sight ${ }^{1}$ appear to continue unchanged although individual trends in blindness are harder to detect because of small numbers affected in each population studied.

In this report we have provided current prevalence rates for diabetic eye disease and visual disability in an inner city population in the UK. When extrapolated to entire populations in geographically defined areas, such figures allow for the costing and purchasing of screening services, audit of the screening cover of the target population and a baseline against which to measure St Vincent Declaration targets.

The authors gratefully acknowledge the support of Liverpool Health Authority and the British Diabetic Association and the invaluable help of Mrs Y. Swain, Mr R. Jackson and the Liverpool Diabetic Eye Screening team.

\section{References}

1. Evans J, Rooney C, Ashwood F, et al. Blindness and partial sight in England and Wales: April 1990-March 1991. Health Trends 1996;28(1):5-12.

2. British Multicentre Study Group. Proliferative diabetic retinopathy: treatment with xenon arc photocoagulation. BMJ 1977;1:739-41.

3. Hercules BL, Gayed II, Lucas SB, Leacock J. Peripheral retinal ablation in the treatment of proliferative diabetic retinopathy: a three year interim report of a randomised controlled study using argon laser. Br J Ophthalmol 1977;61:555-63.

4. Diabetic Retinopathy Study Research Group. DRS Group \#8. Photocoagulation treatment of proliferative diabetic retinopathy. Ophthalmology 1981;88:583-600.

5. Early Treatment Diabetic Retinopathy Study Research Group. Photocoagulation for diabetic macular oedema. Int Ophthalmol Clin 1987;27:265-72.

6. Lee CM, Olk RJ. Modified grid laser photocoagulation for diffuse diabetic macular edema: long-term visual results. Ophthalmology 1991;98:1594-602.

7. Buxton MJ, Sculpher MJ, Ferguson BA, et al. Screening for treatable diabetic retinopathy: a comparison of different methods. Diabet Med 1991;8:371-7.

8. Pugh JA, Jacobson JM, Van Heuven WAJ, et al. Screening for diabetic retinopathy: the wide angle retinal camera. Diabetes Care 1993;16:889-95. 
9. Harding SP, Broadbent DM, Neoh C, White MC, Vora JP. Sensitivity and specificity of photography and direct ophthalmoscopy in screening for sight threatening eye disease: the Liverpool Diabetic Eye Study. BMJ 1995;311:1131-5.

10. Foulds W, McCuish A, Barrie T, et al. Diabetic retinopathy in the West of Scotland: its detection and prevalence, and costeffectiveness of a proposed screening programme. Health Bull 1983;41:318-26.

11. Javitt JC, Canner JK, Sommer A. Cost effectiveness of current approaches to the control of retinopathy in type 1 diabetics. Ophthalmology 1989;96:255-64.

12. Javitt JC, Canner JK, Frank RG, Steinwachs DM, Sommer A. Detecting and treating retinopathy in patients with type 1 diabetes. Ophthalmology 1990;97:483-92.

13. Sculpher MJ, Buxton MJ, Ferguson BA, et al. A relative costeffectiveness analysis of different methods of screening for diabetic retinopathy. Diabet Med 1991;8:644-50.

14. Burnett SD, Woolf CM, Yudkin JS. Developing a district diabetic register. BMJ 1992;305:627-30.

15. Taylor R. Practical community screening for diabetic retinopathy using the Mobile Retinal Camera: report of a 12 centre study. Diabet Med 1996;13:882-8.

16. WHO/IDF Europe. Diabetes Care and Research in Europe: the St Vincent Declaration. Diabet Med 1990;7:360.

17. McLeod BK, Thompson JR, Rosenthal AR. The prevalence of retinopathy in the insulin-requiring diabetic patients of an English country town. Eye 1988;2:424-30.

18. Sparrow JM, McLeod BK, Smith TDW, Birch MK, Rosenthal AR. The prevalence of diabetic retinopathy and maculopathy and their risk factors in the non-insulin-treated diabetic patients of an English town. Eye 1993;7:158-63.

19. Klein R, Klein BEK, Moss SE, Davis MD, DeMets DL. The Wisconsin Epidemiologic Study of Diabetic Retinopathy. II. Prevalence and risk of diabetic retinopathy when age at diagnosis is less than 30 years. Arch Ophthalmol 1984;102:520-6.

20. Klein R, Klein BEK, Moss SE, Davis MD, DeMets DL. The Wisconsin Epidemiologic Study of Diabetic Retinopathy. III. Prevalence and risk of diabetic retinopathy when age at diagnosis is 30 or more years. Arch Ophthalmol 1984;102:527-32.

21. Klein R, Klein BEK, Moss SE, Davis MD, DeMets DL. The Wisconsin Epidemiologic Study of Diabetic Retinopathy. IV. Diabetic Macular Edema. Ophthalmology 1986;91:1464-74.

22. Grey RHB, O'Reilly MD, Morris A. Ophthalmic survey of a diabetic clinic. I. Ocular findings. Br J Ophthalmol 1986;70:797-803.

23. Sjølie AK. Ocular complications in insulin treated diabetes mellitus: an epidemiological study. Acta Ophthalmol (Copenh) 1985;63(Suppl 172):17-20.
24. Kristinsson JK, Stefánsson E, Jónasson F, Gíslason I Björnsson S. Systematic screening for diabetic eye disease in insulin dependent diabetes. Acta Ophthalmol (Copenh) 1994;72:72-8.

25. Kristinsson JK, Stefánsson E, Jónasson F, Gíslason I, Björnsson S. Screening for eye disease in type 2 diabetes mellitus. Acta Ophthalmol 1994;72:341-6.

26. Adardh E, Torffvit O, Agardh CD. The prevalence of retinopathy and associated medical risk factors in type I (insulin dependent) diabetes mellitus. J Intern Med 1989;226:47-52.

27. Agardh E, Torffvit O, Agardh CD. Putative risk factors associated with retinopathy in patients with diabetes diagnosed at or after 30 years of age. Diabet Med 1989;6:724-7.

28. Reenders K, De Nobel E, van den Hoogen HJM, Rutten GEHM, van Weel C. Diabetes and its long-term complications in general practice: a survey in a well-defined population. Family Practice 1993;10:169-72.

29. Jarman B. Underprivileged areas: validation and distribution of scores. BMJ 1984;289:1587-92.

30. Early Treatment Diabetic Retinopathy Study Research Group. Grading diabetic retinopathy from stereoscopic colour fundus photographs: an extension of the modified Airlie House classification. ETDRS report no. 10. Ophthalmology 1991;98:786-806.

31. Retinopathy Working Party. A protocol for screening for diabetic retinopathy in Europe. Diabet Med 1991;8:263-7.

32. Klein R, Klein BEK, Moss SE, et al. Prevalence of diabetes mellitus in Southern Wisconsin. Am J Epidemiol 1984;119:54-61.

33. Morris AD, Boyle DIR, MacAlpine R, et al. The diabetes audit and research in Tayside Scotland (DARTS) study: electronic record linkage to create a diabetes register. BMJ 1997;315:524-8.

34. Klein R. The epidemiology of diabetic retinopathy: findings from the Wisconsin Epidemiologic Study of diabetic retinopathy. Int Ophthalmol Clin 1987;27:230-8.

35. de Courten M, Zimmet P. Screening for non-insulindependent diabetes mellitus: where to draw the line? Diabet Med 1997;14:95-8.

36. Bodansky HJ, Cudworth AG, Whitelocke RAF, Dobree JH. Diabetic retinopathy and its relation to type of diabetes: review of a retinal clinic population. Br J Ophthalmol 1982;66:496-9.

37. Klein R, Klein BEK, Moss SE. Visual impairment in diabetics. Ophthalmology 1984;91:1-9.

38. The Diabetic Retinopathy Study Research Group. Report no. 3. Four risk factors for severe visual loss in diabetic retinopathy. Arch Ophthalmol 1979;97:654-5. 